\title{
A COPD Case-Finding Program in a Large Cohort of HIV-Infected Persons
}

\author{
Eugenia Quiros-Roldan, Maria Chiara Pezzoli, Marialma Berlendis, Elena Raffetti, Alice Ferraresi, \\ Martina Properzi, Paola Rodari, and Francesco Castelli
}

\begin{abstract}
BACKGROUND: COPD screening guidelines in patients with HIV are lacking, and data about its under-diagnosis are still limited. This study aimed to determinate the feasibility of a case-finding program and the prevalence of COPD under-diagnosis in a large cohort of HIV-infected subjects. METHODS: All out-patients attending their routine visit for HIV monitoring at Spedali Civili General Hospital in Brescia, Italy, from February 2015 to January 2016, were enrolled. The case-finding program was structured in three steps: questionnaire administration, pre-bronchodilator spirometry testing measured with a portable spirometer, and post-bronchodilator diagnostic spirometry during a pulmonology appointment. RESULTS: A total of 1,463 subjects were included; the average age was $46.2 \pm 10.3 \mathrm{y}$. Two hundred eighty-two subjects had a positive questionnaire; 190 completed portable spirometry, and approximately 34\% (65 of 190 subjects) reported respiratory impairment; of these 65 subjects, 33 completed diagnostic spirometry, and $66.7 \%$ (22 of 33 ) showed evidence of COPD, including 2 subjects with severe airway obstruction (GOLD stage 3, according to the Global Initiative for Chronic Obstructive Lung Disease). High dropout rates were observed in our program. Individuals with COPD exacerbations showed lower CD4+ cell counts at screening compared to those without acute worsening of symptoms $\left(534\right.$ cells $/ \mathrm{mm}^{3}$ for subjects with GOLD 1 exacerbations and 495 cells $/ \mathrm{mm}^{3}$ for subjects with GOLD 2 exacerbations vs 781 cells $/ \mathrm{mm}^{3}$ for those without acute worsening of symptoms). The positive predictive value of the COPD screening questionnaire and portable spirometry was 33.8\%. CONCLUSIONS: COPD may be underdiagnosed in HIV-infected people, and case-finding programs are an urgent issue to address as part of routine practice in these individuals. Key words: adherence; chronic; HIV; pulmonary; spirometry; case finding; COPD. [Respir Care 2019;64(2):169-175. (c) 2019 Daedalus Enterprises]
\end{abstract}

\section{Introduction}

COPD is a considerable cause of morbidity and mortality in the general population, although there is substantial heterogeneity in COPD prevalence rates, with high levels of COPD under-diagnosis reported worldwide. ${ }^{1-3}$ The increasing number of cigarette smokers in developing countries and the progressive aging of the population account for increasing disease burden. However, COPD prevalence is underestimated because it is not clinically evident until

\footnotetext{
Drs Quiros-Roldan, Pezzoli, Ferraresi, Properzi, Rodari, and Castelli are affiliated with the Department of Infectious and Tropical Diseases, University of Brescia and Spedali Civili General Hospital, Brescia, Italy. Dr Berlendis is affiliated with the Pneumology Unit, Spedali Civili General Hospital, Brescia, Italy. Dr Raffetti is affiliated with the Unit of Hygiene, Brescia University, Brescia, Italy.
}

the disease reaches a moderately advanced stage. Many factors have been associated with COPD under-diagnosis including younger age, lower severity of airway obstruction, and fewer respiratory symptoms. ${ }^{4}$

HIV-infected patients are being diagnosed with COPD more frequently due primarily to the growing number of elderly in this population with consequently longer tobacco exposure..$^{1-3}$ In addition, HIV itself has been identified as an independent risk factor for COPD development. ${ }^{5-7}$ None-

\footnotetext{
Correspondence: Alice Ferraresi, University Department of Infectious and Tropical Diseases, University of Brescia and Spedali Civili General Hospital, Piazzale Spedali Civili 1, 25123, Brescia, Italy. E-mail: alice-ferraresi@hotmail.it
}

DOI: $10.4187 /$ respcare.06247 
theless, COPD screening guidelines as well as management methods in HIV-infected people are lacking, and data about COPD under-diagnosis are still limited. ${ }^{8-10}$ Considering that early diagnosis plays a crucial role in determine COPD prognosis and outcome, it is vital to define new strategies to detect COPD cases in this population. Primary care screening involves risk assessment with a formal prescreening questionnaire and, if positive, implementation of diagnostic spirometry testing. ${ }^{11} \mathrm{We}$ aimed to determine the feasibility of a COPD case-finding program in HIV-positive subjects attending an Italian center for HIV care and, subsequently, to determine the prevalence of under-diagnosed COPD in this setting.

\section{Methods}

\section{Study Design and Population}

This study was performed at the Infectious Disease Unit of Spedali Civili General Hospital in Brescia, Italy, which provides care to approximately 3,800 HIV-positive patients. From February 2015 to January 2016, 1,634 HIV infected out-patients who came to our clinic for routine care were evaluated for the COPD case-finding program. Patients with acute or chronic respiratory illness were excluded ( $n=171$ individuals; among them 154 had a previous diagnosis of $\mathrm{COPD}$ ), leaving 1,463 subjects who were enrolled. This study was conducted in accordance with the 1964 Helsinki Declaration Guidelines and its later amendments, as well as the principles of good clinical practice. This study was approved by the Local Ethical Committee. Written informed consent was obtained for all enrolled subjects.

\section{Testing Procedure}

The COPD screening program was structured in the three steps: administration of a COPD questionnaire, portable spirometry testing to identify subjects who needed further diagnostic evaluation, and post-bronchodilator spirometry. Briefly, the COPD questionnaire was administrated to subjects during their routine HIV clinic visit. Individuals found to be at risk for COPD performed portable spirometry with a portable spirometer during the same visit. Finally, subjects with airway obstruction as measured by the portable spirometer were advised to visit a pneumologist for post-bronchodilator spirometry, with an appointment in the following days.

COPD Questionnaire. We used a 5-question COPD screener tool published for general population, as recommended by the COPD Foundation (http://www.copdfoundation. org/screener.aspx, Accessed September 21, 2018.), which includes the following items: age $\geq 40 \mathrm{y}$, former or cur-

\section{QUICK LOOK}

\section{Current knowledge}

Despite effective antiretroviral therapy, HIV-infected patients are at increased risk for chronic diseases. COPD is a considerable cause of morbidity and mortality in HIV-positive people. In these individuals, guidelines to identify COPD are lacking and data regarding COPD under-diagnosis are still limited.

\section{What this paper contributes to our knowledge}

In this population we observed under-diagnosed COPD. It was difficult to implement a case-finding program in HIV-infected persons. The most appropriate screening tool remains unclear because tests performed more poorly compared to results found in the general population. An additional problem includes inadequate adherence of HIV-infected people to the COPD case-finding program.

rent smoker, chronic cough with phlegm production, shortness of breath, and limited exercise. An HIV specialist administered the questionnaire in a face-to-face interview during a routine clinic visit. All subjects who answered positively to at least 3 questions were invited to perform portable spirometry the same day to determine airway obstruction.

Spirometry With Portable Spirometer. Lung function measurements were performed according to the manufacturer's recommendations using a portable spirometer (Spirometer QM-SP100, Quirumed, Valencia, Spain) at the HIV clinic. Subjects underwent 3 FVC maneuvers, and their mean value was reported as a final result. Incomplete or invalid efforts (ie, efforts in which the subject coughed) were excluded.

$\mathrm{FEV}_{1}$ was also assessed. All subject measurements were performed by the same staff member at the HIV clinic. Subjects with $\mathrm{FEV}_{1} \leq 80 \%$ than predicted, who possibly had COPD, were referred to the pneumology department to undergo diagnostic post-bronchodilator spirometry and to record the number of respiratory symptom exacerbations during the past year. An exacerbation was defined as an acute event characterized by worsening of respiratory symptoms beyond normal day-to-day variations that led to the need for medication. We opted for the cut-off of $\mathrm{FEV}_{1} \leq 80 \%$ predicted because portable spirometers may be inaccurate; moreover, testing was performed by staff of the HIV clinic, not by trained specialists. Therefore, this limit was set to avoid loss of uncertain cases, remanding to the pneumologist the definitive COPD diagnosis. 


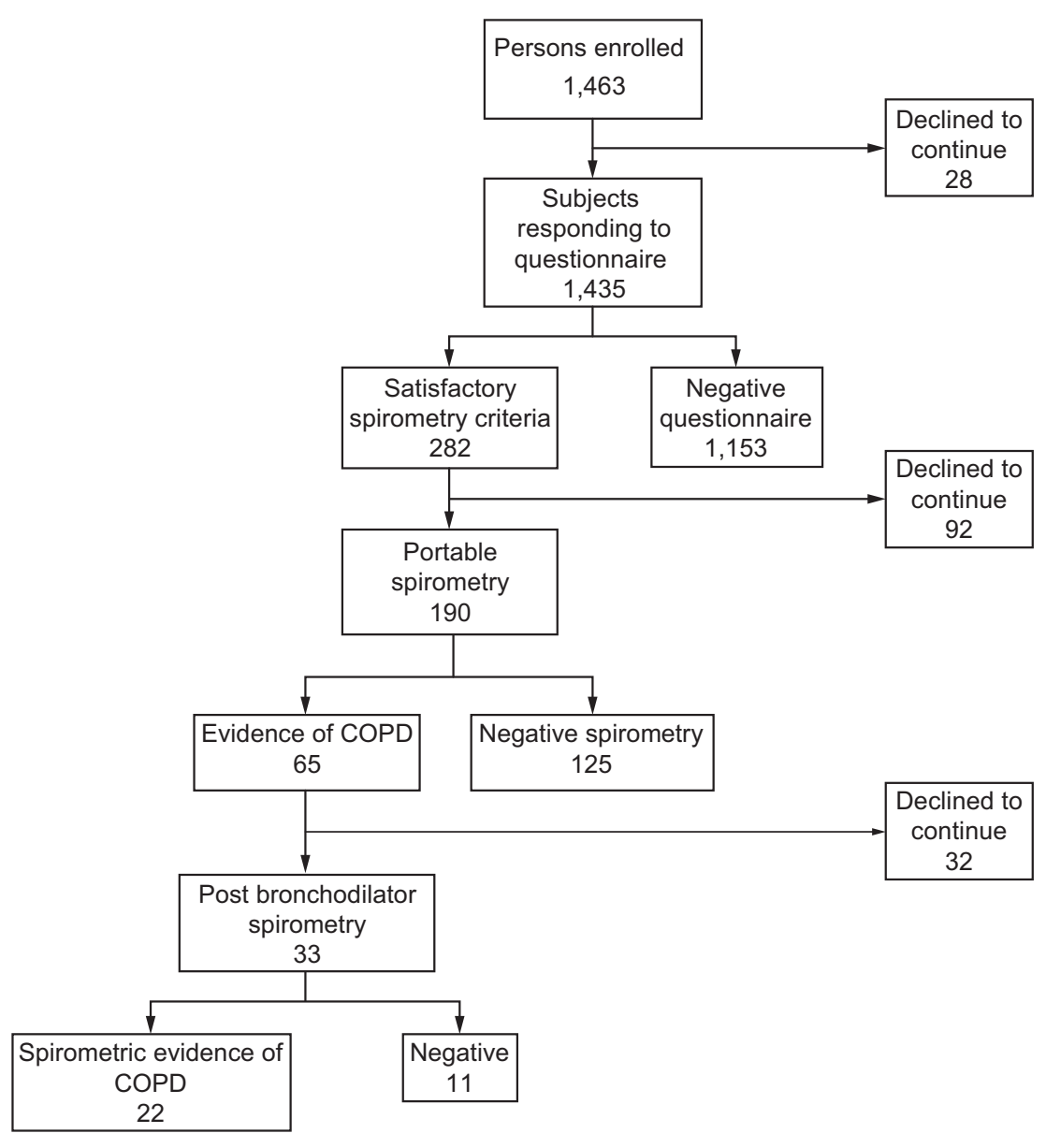

Fig. 1. Flow chart.

Diagnostic Spirometry Testing. Diagnostic spirometry was performed by trained technicians at the Pneumology Unit using Vmax Encore PFT system (CareFusion, San Diego, California). Testing was performed before and $15 \mathrm{~min}$ after administration of $400 \mu \mathrm{g}$ salbutamol via pressurized metered-dose inhaler with a spacer. According to the Global Initiative for Chronic Obstructive Lung Disease (GOLD) guidelines, ${ }^{12}$ airway obstruction was defined as a $\mathrm{FEV}_{1} / \mathrm{FVC}$ ratio $<0.7$. Among subjects with airway obstruction, $\mathrm{FEV}_{1}>80 \%$ predicted characterized mild airway obstruction (GOLD 1). Moderate airway obstruction (GOLD 2) was described as $\mathrm{FEV}_{1} 50-80 \%$ of predicted, and severe airway obstruction (GOLD 3) as $\mathrm{FEV}_{1}<50 \%$ predicted.

\section{Statistical Analysis}

All statistical tests were 2-sided, assumed a level of significance of 0.05, and were performed using Stata 12 software version 12.0 (Stata Corporation, College Station, Texas). The probability that a subject with a positive screening test truly had the disease (positive predictive value) was calculated for the COPD screening questionnaire and portable spirometry.

\section{Results}

From February 2015 to January 2016, a total of 1,463 HIV-positive subjects were enrolled in the COPD case-finding program; 1,435 subjects agreed to participate in the first step (98.1\% participation rate) (Fig. 1). Among participants, $76.3 \%$ were males, and the average age was $46.2 \pm 10.3$ y. Concerning HIV acquisition, $71.9 \%$ of subjects presented with sexual transmission, $24.7 \%$ were intravenous drug users, $0.7 \%$ had a vertical transmission, and risk factors for HIV-infection were unknown for $1.6 \%$ of individuals; $47 \%$ of subjects were current smokers, and $21.1 \%$ were former smokers. Almost all subjects (98.1\%) were on combination antiretroviral therapy. After the initial questionnaire, 124 subjects (92 at portable spirometry and 32 at diagnostic post-bronchodilator spirometry) declined to participate further. 
Table 1. Demographic and Clinical Characteristics According to Case-Finding Program Results

\begin{tabular}{|c|c|c|c|}
\hline & Negative* & Positive* & $P$ \\
\hline Completed COPD screening questionnaire $(n=1,435)$ & 1,153 & 282 & \\
\hline Male, $n(\%)$ & $852(73.9)$ & $218(77.3)$ & .24 \\
\hline Migrant, $n(\%)$ & $197(17.1)$ & $24(8.5)$ & $<.001$ \\
\hline Intravenous drug use, $n(\%)$ & $227(20.5)$ & $121(44.5)$ & $<.001$ \\
\hline Mean (SD) CD4+ cell count, cells $/ \mathrm{mm}^{3}$ & $735.3(322.8)$ & $729.9(347.8)$ & .83 \\
\hline Portable spirometry $(n=190)$ & 125 & 65 & \\
\hline Male, $n(\%)$ & $88(70.4)$ & $56(86.2)$ & .02 \\
\hline$\geq 40 \mathrm{y}, n(\%)$ & $114(91.2)$ & $62(95.4)$ & .26 \\
\hline Migrant, $n(\%)$ & $10(8.0)$ & $5(7.7)$ & .94 \\
\hline Intravenous drug use, $n(\%)$ & $33(52.4)$ & $46(39.0)$ & .08 \\
\hline Mean (SD) CD4+ cell count, cells $/ \mathrm{mm}^{3}$ & $731.9(367.8)$ & $732.4(348.2)$ & .95 \\
\hline \multicolumn{4}{|l|}{ Tobacco smoking } \\
\hline Never smokers, $n(\%)$ & $5(4.0)$ & $1(1.5)$ & .049 \\
\hline Former smokers, $n(\%)$ & $90(72.0)$ & $57(87.7)$ & \\
\hline Current smokers, $n(\%)$ & $30(24.0)$ & $7(10.8)$ & \\
\hline Post-bronchodilator spirometry $(n=33)$ & 11 & 22 & \\
\hline Male, $n(\%)$ & $11(100)$ & $17(77.3)$ & .11 \\
\hline$\geq 40 \mathrm{y}, n(\%)$ & $10(90.9)$ & $22(100)$ & .33 \\
\hline Migrant, $n(\%)$ & $0(0)$ & $1(4.5)$ & $>.99$ \\
\hline Intravenous drug use, $n(\%)$ & $7(77.8)$ & $10(45.5)$ & .13 \\
\hline Mean (SD) CD4+ cell count, cells $/ \mathrm{mm}^{3}$ & $689.4(295.7)$ & $649.0(276.0)$ & .72 \\
\hline \multicolumn{4}{|l|}{ Tobacco smoking } \\
\hline Never smokers, $n(\%)$ & $0(0)$ & $0(0)$ & .54 \\
\hline Former smokers, $n(\%)$ & $11(100)$ & $20(90.9)$ & \\
\hline Current smokers, $n(\%)$ & $0(0)$ & $2(9.1)$ & \\
\hline
\end{tabular}

$\overline{* \text { Negative indicates }}<3$ positive responses on the COPD questionnaire

Positive indicates $\geq 3$ positive responses on the COPD questionnaire

\section{COPD Case-Finding Program Steps}

COPD Screening Questionnaire. Among the 1,435 subjects who completed the questionnaire, $282(19.6 \%)$ had at least 3 out of 5 positive responses to the COPD screening tool and met the clinical indication for portable spirometry. Regarding the questionnaire items, 1,148 subjects $(80.1 \%)$ were age 40 y or older, $981(68.4 \%)$ were former or current smokers, 220 (15.3\%) reported chronic cough with phlegm production, 196 (13.7\%) experienced shortness of breath, and 132 (9.2\%) reported limited exercise. Individuals with at least 3 out of 5 positive responses to the COPD screening tool included a lower proportion of immigrants $(8.5 \%)$ and more intravenous drug users (44.5\%) compared to subjects who did not have 3 positive questionnaire responses (17.1\% and $20.5 \%$, respectively). (Table 1 ).

Spirometry With Portable Spirometer. Among subjects with a positive questionnaire, 190 performed portable spirometry (67.4\%). Respiratory impairment was observed in 65 subjects (34.2\%); impairment was moderate in 60 subjects $\left(\mathrm{FEV}_{1} 60-79 \%\right.$ of predicted) and severe in 5 subjects (FEV $140-59 \%$ of predicted). These subjects were referred to the Pneumology Unit to confirm the diagnosis with additional spirometry. Among subjects with a provisional COPD diagnosis, 32 subjects refused diagnostic spirometry: 4 had a predicted $\mathrm{FEV}_{1}$ of $40-59 \%$ and 28 had a predicted $\mathrm{FEV}_{1}$ of $60-79 \%$. Higher proportions of males (86.2\%) and former and current smokers (98.5\%) were found in subjects with positive portable spirometry compared to individuals with normal testing (70.4\% and 96\%, respectively) (Table 1).

Diagnostic Spirometry. Among subjects referred to the Pneumology Unit, only 33 (50.8\%) completed the program. Of these subjects, diagnostic spirometry confirmed COPD in 22 subjects $(66.7 \%) ; 12(54.5 \%)$ showed mild obstruction (GOLD 1), 8 (36.3\%) had moderate obstruction (GOLD 2), and 2 (9.1\%) had severe airway obstruction (GOLD 3). No exacerbations were reported by individuals with GOLD 3 stage during the previous year; however, 5 of 12 GOLD 1 subjects and 2 of 8 GOLD 2 subjects described at least one exacerbation in the previous 12 months. No differences in demographic and clinical characteristics were found in subjects who underwent or refused to proceed in our program (Table 2). Interestingly, individuals with COPD exacerbations showed significantly 
Table 2. Demographic and Clinical Characteristics Related to Case-Finding Program Participation and Adherence

\begin{tabular}{|c|c|c|c|}
\hline & No & Yes & $P$ \\
\hline Completed COPD screening questionnaire $(n=1,435)$ & 28 & 1,435 & \\
\hline Male, $n(\%)$ & $22(78.6)$ & $1,070(74.6)$ & .63 \\
\hline$\geq 40 \mathrm{y}, n(\%)$ & $24(85.7)$ & $1,148(80.1)$ & .46 \\
\hline Migrant, $n(\%)$ & $4(14.3)$ & $221(15.4)$ & .87 \\
\hline Intravenous drug use, $n(\%)$ & $6(23.1)$ & $348(25.3)$ & .80 \\
\hline Mean (SD) CD4+ cell count, cells $/ \mathrm{mm}^{3}$ & $649.1(416.6)$ & $734.2(328.1)$ & .27 \\
\hline \multicolumn{4}{|l|}{ Tobacco smoking } \\
\hline Never smokers, $n(\%)$ & $16(57.1)$ & $454(31.6)$ & .10 \\
\hline Former smokers, $n(\%)$ & $10(35.7)$ & $676(47.1)$ & \\
\hline Current smokers, $n(\%)$ & $2(7.1)$ & $305(21.3)$ & \\
\hline Adherence to portable spirometry $(n=282)$ & 92 & 190 & \\
\hline Male, $n(\%)$ & $74(80.4)$ & $166(76.1)$ & .41 \\
\hline$\geq 40 \mathrm{y}, n(\%)$ & 87 (94.6) & $200(91.7)$ & .39 \\
\hline Migrant, $n(\%)$ & $9(9.8)$ & $19(8.7)$ & .77 \\
\hline Intravenous drug use, $n(\%)$ & $42(46.2)$ & $85(41.1)$ & .41 \\
\hline Mean (SD) CD4+ cell count, cells $/ \mathrm{mm}^{3}$ & $724.4(314.7)$ & $723.5(366.1)$ & .99 \\
\hline \multicolumn{4}{|l|}{ Tobacco smoking } \\
\hline Never smokers, $n(\%)$ & $4(4.3)$ & $14(6.9)$ & .70 \\
\hline Former smokers, $n(\%)$ & $70(76.1)$ & $152(74.5)$ & \\
\hline Current smokers, $n(\%)$ & $18(19.6)$ & $38(18.6)$ & \\
\hline Adherence to post-bronchodilator spirometry $(n=65)$ & 32 & 33 & \\
\hline Male, $n(\%)$ & $28(87.5)$ & $30(85.7)$ & .83 \\
\hline$\geq 40 \mathrm{y}, n(\%)$ & $30(93.8)$ & $34(97.1)$ & .50 \\
\hline Migrant, $n(\%)$ & $4(12.5)$ & $1(2.9)$ & .13 \\
\hline Intravenous drug use, $n(\%)$ & $16(50.0)$ & $18(54.6)$ & .71 \\
\hline Mean (SD) CD4+ cell count, cells $/ \mathrm{mm}^{3}$ & $803.9(401.1)$ & $657.9(273.0)$ & .11 \\
\hline \multicolumn{4}{|l|}{ Tobacco smoking } \\
\hline Never smokers, $n(\%)$ & $1(3.1)$ & $0(0.0)$ & .22 \\
\hline Former smokers, $n(\%)$ & $26(81.3)$ & $33(94.3)$ & \\
\hline Current smokers, $n(\%)$ & $5(15.6)$ & $2(5.7)$ & \\
\hline
\end{tabular}

lower CD4+ cell counts at screening compared to those without acute symptom worsening $\left(534\right.$ cells $/ \mathrm{mm}^{3}$ for subjects with GOLD 1 with at least one exacerbation vs $781 \mathrm{cell} / \mathrm{mm}^{3}$ for those without acute worsening of symptoms, $P<.01$; and 495 cells $/ \mathrm{mm}^{3}$ for subjects with GOLD 2 with at least one exacerbation vs $781 \mathrm{cell} / \mathrm{mm}^{3}$ for those without acute worsening of symptoms, $P<.01$ ) (Table 3 ). The positive predictive value, or probability that a subject with abnormal test results had COPD, was $33.8 \%$ (95\% CI $22.6-46.6 \%)$ for the COPD screening questionnaire and portable spirometry.

\section{Discussion}

In our cohort of HIV-infected subjects, we had an excellent participation rate in the COPD case-finding program $(98.1 \%)$, and $89.6 \%$ completed the entire program. Interestingly, 1 of every $5 \mathrm{HIV}$-positive individuals screened by the COPD questionnaire had indication to perform spirometry. However, only $67.4 \%$ and $50.8 \%$ of those who qualified for additional diagnostic testing com- pleted portable spirometry and post-bronchodilator spirometry, respectively. Among subjects who completed the casefinding program, 22 of $1,311(1.7 \%)$ met the criteria for GOLD stage 1 or higher.

COPD has been associated with multiple comorbidities including diabetes, cardiovascular diseases, bone mineral density loss, kidney diseases, cancer, and cognitive decline, considering that common pathways have been involved in their pathogenesis. ${ }^{13,14}$ In addition, HIV infection and age are also risk factors for these comorbidities. ${ }^{15}$ Frailty in HIV-infected patients diagnosed with COPD is increasingly important. ${ }^{16}$ COPD is a chronic, slowly progressive disorder characterized by air-flow obstruction; however, it is also a preventable and treatable disease. Thus, early detection and correct diagnosis are extremely important for avoiding premature frailty.

Although almost all subjects invited to join the COPD case-finding program participated, a remarkable proportion failed to complete the program: $32.6 \%$ of individuals with clinical criteria (positive questionnaire) and $49.2 \%$ of subjects with probable COPD $\left(\mathrm{FEV}_{1}<80 \%\right.$ as measured 
Table 3. Demographic, Laboratory, and Clinical Characteristics of Subjects Post-Bronchodilator Spirometry, Stratified by GOLD Stage

\begin{tabular}{|c|c|c|c|c|c|c|}
\hline & $\begin{array}{l}\text { GOLD } 0 \\
(n=11)\end{array}$ & $\begin{array}{l}\text { GOLD } 1 \\
(n=7)\end{array}$ & $\begin{array}{c}\text { GOLD } 1 \text { with } \geq 1 \\
\text { exacerbation }(n=5)\end{array}$ & $\begin{array}{l}\text { GOLD } 2 \\
(n=6)\end{array}$ & $\begin{array}{c}\text { GOLD } 2 \text { with } \geq 1 \\
\text { exacerbation }(n=2)\end{array}$ & $\begin{array}{l}\text { GOLD } 3 \\
(n=2)\end{array}$ \\
\hline Mean (SD) age, y & $49(6)$ & $50(5)$ & $54(2)$ & $54(5)$ & $53(7)$ & $55(3)$ \\
\hline Male, $n(\%)$ & $11(100)$ & $5(71)$ & $5(100)$ & $4(66,7)$ & $2(100)$ & $1(50)$ \\
\hline \multicolumn{7}{|l|}{ Risk factors for HIV transmission } \\
\hline Sexual intercourse, $n(\%)$ & $2(18)$ & $4(57)$ & $3(60)$ & $5(83)$ & 0 & 0 \\
\hline Intravenous drug use, $n(\%)$ & $7(64)$ & $3(43)$ & $2(40)$ & $1(17)$ & $2(100)$ & $2(100)$ \\
\hline Vertical, $n(\%)$ & 0 & 0 & 0 & 0 & 0 & 0 \\
\hline Not available, $n(\%)$ & $2(18)$ & 0 & 0 & 0 & 0 & 0 \\
\hline Mean (SD) CD4 + cell count, cells $/ \mathrm{mm}^{3}$ & $689(296)$ & $781(220)$ & $543(38)$ & $781(338)$ & 495 (204) & $238(88)$ \\
\hline HIV-RNA < 37 copies/mL, $n(\%)$ & $11(100)$ & $7(100)$ & $5(100)$ & $6(100)$ & $2(100)$ & $2(100)$ \\
\hline Receiving cART, $n(\%)$ & $11(100)$ & $7(100)$ & $5(100)$ & $6(100)$ & $2(100)$ & $2(100)$ \\
\hline \multicolumn{7}{|c|}{$\begin{array}{l}\text { A total of } 33 \text { subjects reached the post-bronchodilator point of the process. } \\
\text { GOLD = Global Initiative for Chronic Obstructive Lung Disease } \\
\text { cART = combination antiretroviral therapy }\end{array}$} \\
\hline
\end{tabular}

by portable spirometry) did not pursue the next screening step (ie, portable spirometry or post-bronchodilator spirometry). Recently, other investigators ${ }^{9,10,17}$ reported high dropout rates in COPD screening programs including people with HIV infection. High dropout rates have also been reported in the general population: a recent study found that more than half $(57.1 \%)$ of subjects with COPD who underwent pre-bronchodilatator spirometry refused to undergo post-bronchodilator spirometry. ${ }^{18} \mathrm{We}$ did not find any demographic or epidemiological factors associated with a successful program to detect COPD cases. There may be a lack of COPD risk perception among HIV-infected people, despite the high proportion of smokers in this population. These data show that many barriers remain to implementing COPD screening programs, contributing to the high rates of under-diagnosis (eg, ignorance of risk involved, fear of being forced to stop smoking, lack of time).

Subjects on stable combination antiretroviral therapy could have inaccurate perceptions of their health and, in the absence of severe symptoms, may only be focused on CD4 + cell count and HIV viral load. This lack of attention may lead to a decline in awareness and thus partial adherence to a COPD screening program. In fact, $98 \%$ of subjects included in our study were on stable combination antiretroviral therapy with optimal viro-immunological values; the improvement of their own care by participating in our program was not largely appreciated. COPD was not recognized in 22 screened subjects $(1.7 \%)$, as well in individuals who reported exacerbations during the previous year ( 7 of 22). These findings are in line with others in the literature, confirming the high rate of under-diagnosed COPD and other obstructive lung diseases both in the general population and in HIV-infected individuals.9,10,17-19

Portable spirometry and formal laboratory-based spirometry have demonstrated an acceptable correlation in subjects with ${ }^{20}$ and without ${ }^{21,22}$ obstructive lung disease.
Very few data are available about portable spirometer performance in the HIV-positive population. Shirley et al ${ }^{9}$ showed that questionnaire administration together with abnormal peak flow (obtained by portable spirometry) was a poor predictor of COPD in HIV-infected subjects (sensitivity $20 \%$, specificity $93 \%$, positive predictive value $14.3 \%$, negative predictive value 95\%). Similarly, Lambert et $\mathrm{al}^{17}$ reported a high dropout rate in their COPD screening program: only $30 \%$ of HIV-infected people completed spirometry and, of them, $26 \%$ were diagnosed with COPD. In our study the positive predictive value of the COPD questionnaire plus portable spirometry was $33.8 \%$. Our results are therefore comparable to other studies conducted in HIV-infected individuals. These tests performed more poorly in our research compared to previous studies conducted in the general population ${ }^{11,22}$; as a consequence the most appropriate screening tool in HIV-infected subjects remains unclear. Age, education, socioeconomic status, and comorbidities could be confounding factors, altering screening performance.

Finally, we confirmed previous data showing that subjects with more advanced immunosuppression may show worse respiratory symptoms. ${ }^{5,23}$ The strength of this study is the large sample size that includes all patients followed in our HIV clinic, without restrictive exclusion (except previous or current respiratory diseases) or inclusion criteria. However, our study has some limitations. First, the subjects' reasons for dropping out of the case-finding program were not recorded. Second, pulmonary function tests were only performed in subjects with a previous positive step: therefore, performance of our program in people with HIV infection was not assessed. Further studies are needed to test the performance of this case-finding program in HIV infected patients by completing diagnostic tests in the entire cohort, because we have not informations 


\section{COPD Case-Finding in SubJects With HIV}

about the possibility of false negative results of our screening planning.

\section{Conclusions}

Obstructive lung diseases remain under-diagnosed in HIV-infected people, and COPD screening programs are an urgent issue to address as part of routine care of these patients. Further studies are necessary to increase the participation in and completion of COPD screening by HIVinfected individuals. Possible future strategies to improve acceptance in this population include clear explanations of COPD, defining diagnostic procedures, and education about the importance of completing the entire screening program.

\section{ACKNOWLEDGMENTS}

We thank the COPD in HIV Study Group (Roberto Allegri MD, Filippo Castelnuovo MD, Issa El Hamad MD, Emanuele Focà MD, Ilaria Izzo MD) of the University Department of Infectious and Tropical Diseases, University of Brescia and Spedali Civili General Hospital, Brescia, Italy.

\section{REFERENCES}

1. Lamprecht B, Soriano JB, Studnicka M, Kaiser B, Vanfleteren LE, Gnatiuc L, et al. Determinants of underdiagnosis of COPD in national and international surveys. Chest 2015;148(4):971-985.

2. Markun S, Rosemann T, Dalla-Lana K, Steurer-Stey C. The impact of case finding on the recruitment yield for COPD Research in primary care: an observational study. Respiration 2016;92(5):308315.

3. Casas Herrera A, Montes de Oca M, López Varela MV, Aguirre C, Schiavi E, Jardim JR, PUMA Team. COPD underdiagnosis and misdiagnosis in a high-risk primary care population in four Latin American Countries. A key to enhance disease diagnosis: the PUMA Study. PLoS One 2016;11(4):e0152266.

4. Talamo C, Montes de Oca M, Halbert R, Perez-Padilla R, Jardim JR, Muiño A, et al. Diagnostic labeling of COPD in five Latin American cities. Chest 2007;131(1):60-67.

5. Drummond MB, Kirk GD, Astemborski J, Marshall MM, Mehta SH, McDyer JF, et al. Association between obstructive lung disease and markers of HIV infection in a high-risk cohort. Thorax 2012;67(4): 309-314.

6. Drummond MB, Huang L, Diaz PT, Kirk GD, Kleerup EC, Morris A, et al. Factors associated with abnormal spirometry among HIVinfected individuals. AIDS 2015;29(13):1691-1700.

7. Nakamura $H$, Tateyama M, Tasato D, Haranaga S, Ishimine $T$, Higa F, et al. The prevalence of airway obstruction among Japanese HIVpositive male patients compared with general population: a casecontrol study of single center analysis. J Infect Chemother 2014; 20(6):361-364.

8. Ryom L, Boesecke C, Gisler V, Manzardo C, Rockstroh JK, Puoti, M, et al. Essentials from the 2015 European AIDS Clinical Society
(EACS) guidelines for the treatment of adult HIV-positive persons. HIV Med 2016;17(2):83-88.

9. Shirley DK, Kaner RJ, Glesby MJ. Screening for chronic obstructive pulmonary disease (COPD) in an urban HIV clinic: a pilot study. AIDS Patient Care STDS 2015;29(5):232-239.

10. Ghadaki B, Kronfli N, Vanniyasingam T, Haider S. Chronic obstructive pulmonary disease and HIV: are we appropriately screening? AIDS Care 2016;28(10):1338-1343.

11. US Preventive Services Task Force (USPSTF), Siu AL, BibbinsDomingo K, Grossman DC, Davidson K, Epling JW Jr, et al. Screening for chronic obstructive pulmonary disease: US Preventive Services Task Force recommendation statement. JAMA 2016;315(13): 1372-1377.

12. Vogelmeier CF, Criner GJ, Martinez FJ, Anzueto A, Barnes PJ, Bourbeau $\mathrm{J}$ et al. Global strategy for the diagnosis, management and prevention of chronic obstructive lung disease 2017 Report: GOLD executive summary. Respirology 2017;22(3):575-601.

13. Camiciottoli G, Bigazzi F, Magni C, Bonti V, Diciotti S, Bartolucci $\mathrm{M}$, et al. Prevalence of comorbidities according to predominant phenotype and severity of chronic obstructive pulmonary disease. Int J Chron Obstruct Pulmon Dis 2016;11:2229-2236.

14. Miłkowska-Dymanowska J, Białas AJ, Zalewska-Janowska A, Górski P, Piotrowski WJ. Underrecognized comorbidities of chronic obstructive pulmonary disease. Int $\mathbf{J}$ Chron Obstruct Pulmon Dis 2015;10:1331-1341.

15. Guaraldi G. The transition from co-morbidities to geriatric syndromes in HIV. Germs 2016;6(3):79-81.

16. Akgün KM, Tate JP, Oursler KK, Crystal S, Leaf DA, Womack JA, et al. Association of chronic obstructive pulmonary disease with frailty measurements in HIV-infected and uninfected Veterans. AIDS 2016;30(14):2185-2193.

17. Lambert AA, Drummond MB, Kisalu A, Moxley J, Keruly J, Moore $\mathrm{RD}$, et al. Implementation of a COPD screening questionnaire in an outpatient HIV clinic. COPD 2016;13(6):767-772.

18. Fu SN, Yu WC, Wong CK, Lam MC. Prevalence of undiagnosed airflow obstruction among people with a history of smoking in a primary care setting. Int J Chron Obstruct Pulmon Dis 2016;11: 2391-2399.

19. Ulrik CS, Løkke A, Dahl R, Dollerup J, Hansen G, Cording PH, et al. Early detection of COPD in general practice. Int $\mathrm{J}$ Chron Obstruct Pulmon Dis 2011;6:123-127.

20. Bambra G, Jalota L, Kapoor C, Mills PK, Vempilly JJ, Jain VV. Office spirometry correlates with laboratory spirometry in patients with symptomatic asthma and COPD. Clin Respir J 2017;11(6):805811.

21. Puri V, Zoole JB, Musick J, Krupnick AS, Kreisel D, Crabtree TD, et al. Handheld office-based spirometry versus laboratory spirometry in low-risk patients undergoing lung resection. Innovations (Phila) 2011;6(4):257-261

22. Labor M, Vrbica Ž, Gudelj I, Labor S, Plavec D. Diagnostic accuracy of a pocket screening spirometer in diagnosing chronic obstructive pulmonary disease in general practice: a cross sectional validation study using tertiary care as a reference. BMC Fam Pract 2016; 17(1): 112 .

23. Attia EF, Akgün KM, Wongtrakool C, Goetz MB, Rodriguez-Barradas $\mathrm{MC}$, Rimland $\mathrm{D}$, et al. Increased risk of radiographic emphysema in HIV is associated with elevated soluble CD4 and nadir CD4. Chest 2014;146(6):1543-1553. 